\title{
Reducing the risk of infection in the elderly by dietary intake of yoghurt fermented with Lactobacillus delbrueckii ssp. bulgaricus OLL1073R-1
}

\author{
Seiya Makino ${ }^{1}$, Shuji Ikegami ${ }^{1}$, Akinori Kume ${ }^{1}$, Hiroshi Horiuchi ${ }^{2}$, Hajime Sasaki ${ }^{1}$ and Naoki Orii ${ }^{1}$ \\ ${ }^{1}$ Food Science Institute, Meiji Dairies Corporation, 540 Naruda, Odawara, Kanagawa 250-0862, Japan \\ ${ }^{2}$ Research and Development Centre, Meiji Dairies Corporation, 540 Naruda, Odawara, Kanagawa 250-0862, Japan
}

(Received 19 November 2009 - Revised 11 March 2010 - Accepted 1 April 2010 - First published online 21 May 2010)

Immune senescence potentially leads to an increased risk of infections. It is desirable to augment the immune system and protect against infections by daily consumption of immunostimulatory food. The present study evaluated whether the intake of yoghurt fermented with Lactobacillus delbrueckii ssp. bulgaricus (L. bulgaricus) OLL1073R-1 has an effect on resistance to the common cold. We conducted two independent studies, in which fifty-seven (median age 74.5 years) and eighty-five healthy elderly individuals (median age 67.7 years) were participants. In each study, the subjects were divided into two groups based on age and sex and instructed to eat $90 \mathrm{~g}$ yoghurt or drink $100 \mathrm{ml}$ milk once per $\mathrm{d}$ over an 8 - or 12-week period. A meta-analysis of the results of these two independent studies showed the risk of catching the common cold was about $2 \cdot 6$ times lower (OR $0.39 ; P=0.019$ ) in the yoghurt group than in the milk group and the increase of natural killer cell activity was significantly higher in the yoghurt group than in the milk group $(P=0 \cdot 028)$. In addition, the quality of life score for the 'eye/nose/throat' system after intake was significantly higher in the yoghurt group than in the milk group and the improvement of the score was correlated with the promotion of natural killer cell activity. In conclusion, consumption of yoghurt fermented with L. bulgaricus OLL1073R-1 augmented natural killer cell activity and reduced the risk of catching the common cold in elderly individuals.

Infection: Elderly: Yoghurt: Lactobacillus delbrueckii ssp. bulgaricus OLL1073R-1

The proportion and absolute number of individuals above the age of 65 years are steadily increasing in most countries, particularly in industrialised nations. It is recognised that elderly individuals suffer from not only common age-related illness, including atherosclerosis, Alzheimer's dementia, diabetes mellitus and osteoporosis, but more frequent and more severe infections than younger individuals. The reasons for this include epidemiological elements, immunosenescence and malnutrition, as well as a large number of age-associated physiological and anatomical alterations ${ }^{(1)}$. Human immune function undergoes adverse changes with ageing. This immune senescence potentially leads to an increased risk of infections and certain cancers in the elderly ${ }^{(2,3)}$. It has also been reported that decreases in immune function in the elderly will increase morbidity in the future ${ }^{(4)}$.

Recently, there have been a number of reports on the healthpromoting effects of lactic acid bacteria as probiotics. Among them, reports on their potential to affect the immune system have been notable. In a human study, the consumption of some probiotics was shown to enhance cell-mediated immune responses in the elderly ${ }^{(5,6)}$ and to augment the natural killer cell activity of peripheral blood mononuclear cells in healthy individuals with low levels of natural killer cell activity $^{(7)}$.
Lactobacillus delbrueckii ssp. bulgaricus (L. bulgaricus) OLL1073R-1, a polysaccharide-producing lactic acid bacterial strain, has been confirmed by studies using mice to exhibit more marked effects on the immune system than other lactic acid bacteria. The cell body of L. bulgaricus OLL1073R-1 exerted host-mediated anti-tumour activity in mice ${ }^{(8)}$. It has also been reported that the polysaccharides produced by this strain exhibit mitogenic activity ${ }^{(9)}$, macrophage activation ${ }^{(10)}$ and interferon- $\gamma$-inducing activity ${ }^{(11)}$. Moreover, the enhancement of natural killer cell activity in mouse spleen cells was confirmed after the oral administration of these polysaccharides or yoghurt fermented with this strain ${ }^{(11)}$.

From these reports, the daily intake of yoghurt fermented with L. bulgaricus OLL1073R-1 including its cell body and immunostimulatory polysaccharides is considered to induce the activation of biological defence mechanisms including natural killer cells and to exhibit infection-preventing effects against pathogens such as viruses.

The aim of the present study is to evaluate whether the intake of yoghurt fermented with L. bulgaricus OLL1073R-1 improves the values of immune system parameters that contribute to biological defence in the elderly and if it has a preventive effect against respiratory tract infections, such as the common cold and influenza virus infection.

Abbreviations: Con A, concanavalin A; cpm, counts per min; QOL, quality of life.

* Corresponding author: Seiya Makino, fax +81 46537 3619, email seiya_makino@meiji-milk.com 


\section{Materials and methods}

\section{Subjects}

We conducted two independent studies, the Funagata study and the Arita study. Subjects were screened by clinical examinations and structured interviews to ensure that they were in good health. Inclusion criteria were: residents of Funagata or Arita town who are in good health with no previous history of relevant physical or psychiatric illness. Exclusion criteria were: any recent history of virus infection, cancer, or immunological disorders and abnormalities in haematological or biochemical serum parameters. Some chronic diseases that are found often in the elderly such as diabetes, vascular disease and muscle-bone diseases were not excluded.

In the Funagata study, the subjects were healthy residents of Funagata Town, Yamagata Prefecture, Japan aged 40 years or over who had undergone regular health screening in Funagata. In the Arita study, the subjects were healthy residents of Arita Town, Saga Prefecture, Japan aged 60 years or over.

Before their participation in these studies, written consent was obtained from all subjects after the physician-in-charge had explained the study to the group. In addition, these studies received the approval of the Ethics Committee of the Division of Research and Development of Meiji Dairies Corporation, and it was performed in accordance with the Declaration of Helsinki.

\section{Diets}

The test food was yoghurt prepared using two lactic acid bacterial strains, i.e. L. bulgaricus OLL1073R-1 and Streptococcus thermophilus OLS3059 (1073R-1 yoghurt). These strains were originally isolated from traditional Bulgarian yoghurt. The cell counts of L. bulgaricus OLL1073R-1 and S. thermophilus OLS3059 in the yoghurts were $2 \cdot 0-3.5 \times 10^{8}$ colonyforming units/g and $6.3-8.8 \times 10^{8}$ colony-forming units/g, respectively. The extracellular polysaccharides in the yoghurts represented $36.5-68.0 \mathrm{mg} / \mathrm{kg}$, as measured by the phenolsulfuric acid method ${ }^{(12)}$. Milk was used as a reference food. Both the test and reference foods were delivered to the residence of each subject once per week under refrigeration and stored in a refrigerator until intake.

\section{Study design}

The studies followed a simultaneous comparative design to compare the yoghurt and milk groups. The subjects were instructed to eat $90 \mathrm{~g}$ yoghurt or drink $100 \mathrm{ml}$ milk once per d over an 8-week (Funagata study; 13 March 2005-7 May 2005) or 12-week period (Arita study; 14 November 2006-5 February 2007).

During the period of intake, the subjects were requested to avoid the intake of yoghurt other than the test food and taking drugs including antibiotics except for any medication they were receiving for current diseases. The intake of other health-promoting foods was not restricted, but if dairy products or fermented milk products were ingested, the subjects were requested to record the instances in monitor notebooks that were distributed in advance. The subjects were also instructed to check the symptoms that they had using a 'cold symptoms checklist' if they noted symptoms of the common cold.

Interviews and blood sampling were performed twice, before the beginning and after the end of the intake period. In the Arita study, in addition to an interview, we performed a quality of life (QOL) survey. At the first interview, questions associated with lifestyle and health status were asked to compare the risks of infection in the milk and the yoghurt groups. The questions covered the following items: degree of usual physical activity, current diseases, frequency of smoking, drinking alcohol, physical exercises, and self-awareness of susceptibility to catching the common cold.

\section{Cold symptoms checklist}

All subjects were instructed to track any symptoms they had on a 'cold symptoms checklist' if they noted symptoms of the common cold. The common cold symptoms in this checklist contained the following items: cough, sneezing, stuffy nose, runny nose, sore throat, red throat, swollen throat, headache, temperature, ache, painful articulations, fatigue, loss of appetite. These symptoms are associated with the common cold and influenza virus infection. Finally, after checking this cold-symptoms checklist and their body temperature records, a medical doctor confirmed whether each subject had caught a common cold during the study. The occurrence of influenza virus infection was confirmed by checking whether the subject had received hospital treatment for influenza virus infection during the study.

\section{Diary (monitor notebook)}

Monitor notebooks were distributed to all subjects in advance for them to record the following items daily during the study: (a) body temperature on awakening; (b) whether the test or reference food was taken; (c) if yoghurt or fermented dairy products other than the test food were eaten, the product names and amount consumed (in g); (d) changes in physical condition, etc. These monitor notebooks were used for judging discontinuation of the study protocol and exclusion from the data analysis. A frequency of intake of the test or reference food, one serving of which was intended to be taken daily at an appropriate time, $<80 \%$ was deemed insufficient. Those who ate yoghurt other than the test food with the test or reference food and these who developed a disease and took drugs including antibiotics under the instruction of a physician during the study were excluded from analyses.

\section{Interviews and quality of life survey questionnaires}

Interviews were performed concerning general physical condition, particularly the occurrence of the common cold and influenza virus infection.

A QOL survey was performed using a forty-six-item questionnaire during an interview concerning the physical and mental condition of the subjects before the beginning and after the end of the intake period (Table 1). The four choices concerning each item were scored as follows: 4 , no symptoms; 3, unusual; 2, occasional; 1, frequent. According to the topics of the questions, the forty-six items were grouped into eight organ categories, i.e. respiration, skin, 
Table 1. Quality of life questionnaire items asked in the Arita study

\begin{tabular}{|c|c|}
\hline Organ categories & Items \\
\hline Respiration & Shortness of breath, phlegm or coughing \\
\hline Skin & Rash, dry skin, skin itching \\
\hline Mental condition & $\begin{array}{l}\text { Lack of general motivation, irritation, stress, } \\
\text { depression, sleeplessness, waking at night, } \\
\text { waking early in morning, failure of memory, } \\
\text { sluggish feeling, awareness of health }\end{array}$ \\
\hline Eye/nose/throat & $\begin{array}{l}\text { Dim eyes, eye fatigue, eye itching, dark } \\
\text { circles under eyes, runny nose or nasal } \\
\text { congestion, sore throat, thirstiness }\end{array}$ \\
\hline Kidney & $\begin{array}{l}\text { Fatigued feeling in morning, leg swelling, } \\
\text { waking for urination more than twice } \\
\text { a night, urination at night, easily fatigued, } \\
\text { unrelieved feeling after urination }\end{array}$ \\
\hline Digestive system & $\begin{array}{l}\text { Poor appetite, bloated feeling or stomach } \\
\text { ache, diarrhoea, tasteless feeling, } \\
\text { constipation, haemorrhoids }\end{array}$ \\
\hline $\begin{array}{l}\text { Musculoskeletal } \\
\text { system }\end{array}$ & $\begin{array}{l}\text { Stiff neck or back pain, arthralgia, } \\
\text { muscular pain, numbed hands or feet }\end{array}$ \\
\hline Others & $\begin{array}{l}\text { Headache, palpitations, instantaneous } \\
\text { orthostatic hypotension, buzzing in the } \\
\text { ears, hands and feet get cold easily, } \\
\text { sweating heavily, flushed feeling, } \\
\text { swelling or bleeding at gingivae, chapped lips }\end{array}$ \\
\hline
\end{tabular}

mental condition, eye/nose/throat/, kidney, digestive system, musculoskeletal system, and others (Table 1). After the end of intake, a survey concerning the occurrence of the common cold and influenza during the intake period was performed.

\section{Blood sampling and immune measurement}

Tests of immune function (natural killer cell activity and lymphocyte blastoid transformation by concanavalin A (Con A)) were performed before the beginning and after the end of the intake period by sampling about $30 \mathrm{ml}$ blood each time. The subjects fasted (drinking of water was permitted) after 10.00 hours on the day before blood sampling, and blood was sampled on the morning of the sampling day. These blood tests were performed by Mitsubishi Chemical Corp. (Funagata study) or SRL Inc. (Arita study).

Natural killer cell activity was assessed by specific target lysis against ${ }^{51} \mathrm{Cr}$-labelled $\mathrm{K} 562$ cells at an effector:target ratio of 20:1 (Funagata study) or 50:1 (Arita study). Peripheral blood mononuclear cells were separated as target cells by density gradient centrifugation and washed twice in PBS. The cells were incubated with ${ }^{51} \mathrm{Cr}$-labelled $\mathrm{K} 562$ cells for $3.5 \mathrm{~h}$ (Funagata study) or $4 \mathrm{~h}$ (Arita study). Then, the supernatant fraction was harvested, and the counts per min $(\mathrm{cpm})$ were counted in a gamma counter. Lytic activity was expressed as percentage cytotoxicity as calculated by the following formula:

$$
\begin{aligned}
& \text { Percentage cytotoxicity } \\
& \qquad \begin{array}{l}
((\text { experiment } \mathrm{cpm})-(\text { minimum } \mathrm{cpm})) / \\
\quad((\text { maximum cpm })-(\text { minimum cpm })) \times 100 .
\end{array}
\end{aligned}
$$

T lymphocyte blastoid transformation was evaluated by their $\left[{ }^{3} \mathrm{H}\right]$ thymidine uptake after Con A stimulation. Peripheral blood mononuclear cells were separated by density gradient centrifugation and washed twice in PBS. The cells were then adjusted to a concentration of $5 \times 10^{5}$ cells $/ \mathrm{ml}$ in Roswell Park Memorial Institute (RPMI) 1640 medium with $10 \%$ fetal bovine serum and then stimulated with Con A. After being cultured for $65.5 \mathrm{~h}$ (Funagata study) or $64 \mathrm{~h}$ (Arita study) at $37^{\circ} \mathrm{C}$ in $5 \% \mathrm{CO}_{2},\left[{ }^{3} \mathrm{H}\right]$ thymidine was added to each well, and then the cells were cultured for a further $8 \mathrm{~h}$ at $37^{\circ} \mathrm{C}$ in $5 \% \mathrm{CO}_{2}$. The contents of the wells were harvested onto a glass filter using a cell harvester. $\left[{ }^{3} \mathrm{H}\right]$ thymidine uptake was measured using a liquid scintillation counter.

\section{Adverse events}

Concerning severe adverse events that occurred during the period of intake of yoghurt or milk, the symptoms, severity, date of appearance, test or reference food intake, treatments, and outcomes were recorded, and their relationships with the test food were evaluated.

\section{Statistical analyses}

The characteristics of the subjects (sex, age, lifestyle, state of health, immune function and QOL) were compared between the yoghurt and milk groups. Categorical variables such as sex, lifestyle and state of health were compared between the two groups using the $\chi^{2}$ test. Age, the results of laboratory examinations, immune functions before the beginning of intake (baseline) and total QOL score were compared between the two groups using the Student's $t$ test and Mann-Whitney $U$ test.

Concerning natural killer cell activity, the baseline values were categorised into low (lower than the lower limit of the normal range), normal (within the normal range) and high (higher than the upper limit of the normal range) according to the standard values of Mitsubishi Chemical Corp. (Funagata study) or SRL Inc. (Arita study). These ranges had been defined by Mitsubishi Chemical Corp. or SRL Inc. as the range covering $95 \%$ of the natural killer cell activity of healthy individuals. Changes in the values between before and after intake in the low-, normal- and high-value groups were analysed using the Student's paired $t$ test in both the milk and yoghurt groups. Meta-analysis was also performed by integrating the results of these two independent cohort studies using the general variance-based method for mean differences on the same scale $e^{(13,14)}$

Concerning QOL scores, the total score of the forty-six items, the scores for each of the forty-six items, and the total scores for each of the eight categories were compared between before and after intake within each group and between groups after intake. Comparisons within each group were performed using Wilcoxon's signed-rank test. Comparisons between the groups were performed using the Mann-Whitney $U$ test.

The occurrence of the common cold and influenza during the intake period was compared between groups using Fisher's exact test. Meta-analysis was also performed by integrating the results of these two independent cohort studies using the Mantel-Haenszel method ${ }^{(13,14)}$.

Concerning the level of the promotion of immune functions, the percentage changes in the values of each item relative to their baseline values were divided into four quartiles, and 


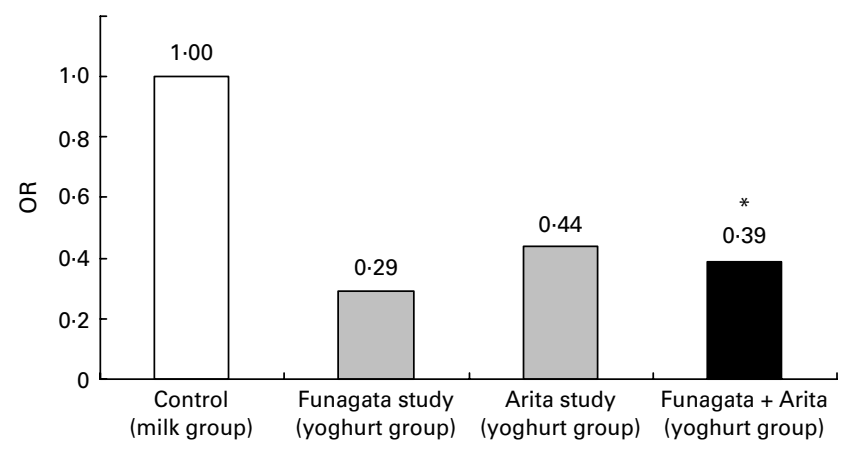

Fig. 1. Risk of catching the common cold in the milk and yoghurt (fermented with Lactobacillus delbrueckii ssp. bulgaricus OLL1073R-1) groups in two independent studies. A meta-analysis was performed by integrating the results of these two independent studies using the Mantel-Haenszel method. * $P<0.05$

the values in the first quartile were regarded as decreases, those in the second and third quartiles as no change, and those in the fourth quartile as increases. Changes in QOL were categorised as 'improved' when the percentage changes in the total score of the forty-six items and total scores for each of the seven categories after intake relative to those before intake were $\geq 10 \%$, as 'no change' when they were -10 to $10 \%$, and as 'declined' when they were $\leq-10 \%$. The correlation between the improvements in immune functions and QOL was analysed using Spearman's rank correlation coefficient.

Statistical analyses were performed using the statistical software package SPSS14.0J (SPSS Inc., Chicago, IL,

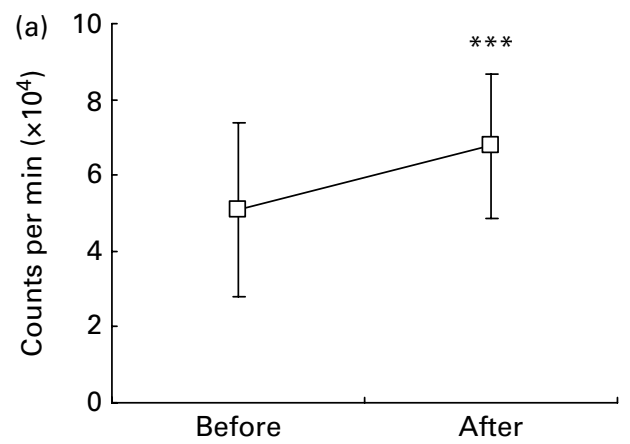

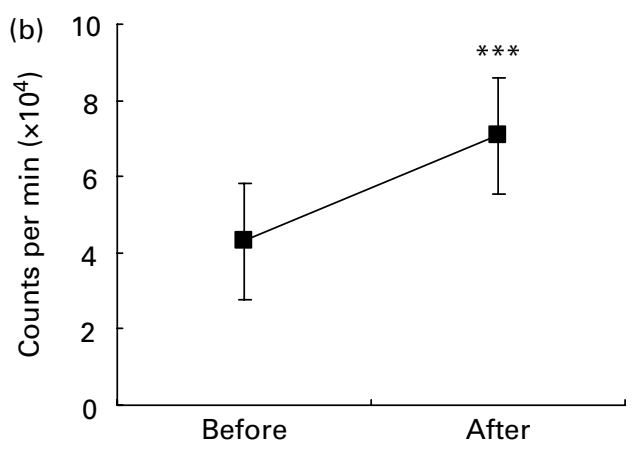

USA, 2005). Two-tailed tests were performed at a significance level of $5 \%$.

\section{Results}

\section{Characteristics of subjects}

In the Funagata study, sixty subjects were selected and divided randomly into two groups of thirty subjects that were comparable in age and sex. As three dropped out during the study, the number of subjects at the end of the study was fifty-seven (median age 74.5 (range 69-80) years), of whom twenty-eight were in the milk group, and twenty-nine were in the yoghurt group.

In the Arita study, 112 subjects were selected. Since seventeen subjects were selectively assigned to the milk or yoghurt group, ninety-five subjects were randomised to the two groups without unevenness in age, sex, or yoghurt intake habit, resulting in the assignment of forty-six to the milk group and forty-nine to the yoghurt group. Since nine subjects were absent due to personal reasons on the first day of the study, the number of subjects who participated in the study decreased to 103 and randomised subjects were eighty-seven (forty-three in the milk group and forty-four in the yoghurt group). As two individuals dropped out during the study, the number of subjects at the end of the study was 101, of whom eighty-five were randomised subjects (median age 67.7 (range 59-84) years), forty-two were in the milk group, and forty-three were in the yoghurt group.

The compliance rate was $80 \%$ or higher in all subjects, with no significant difference between the two groups. Nobody ate

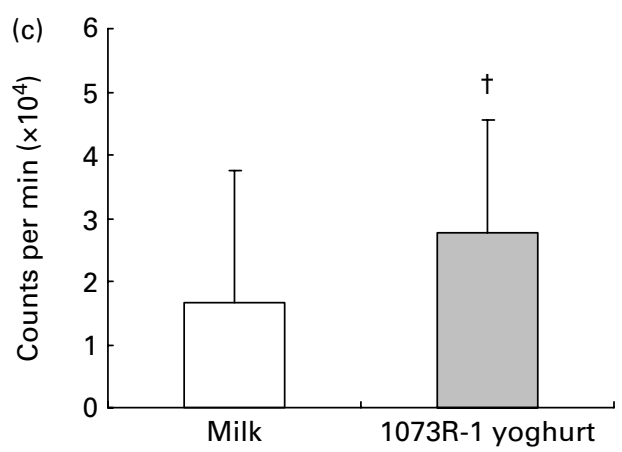

Fig. 2. Lymphocyte blastoid transformation in the milk ( $n$ 28) (a) and yoghurt (fermented with Lactobacillus delbrueckii ssp. bulgaricus OLL1073R-1) ( $n$ 29) (b) groups and changes in the values between before and after intake (c) in the Funagata study. Values are means, with standard deviations represented by vertical bars. ${ }^{* * *}$ Mean value was significantly different from that before the intervention $(P<0.001)$. $†$ Mean value was significantly different from that of the milk group $(P<0.05)$. 
yoghurt other than the test food with the test or reference food or developed a disease requiring drugs including antibiotics except for those who caught the common cold or were infected with the influenza virus during the study.

The characteristics of the randomised subjects were compared between the test and reference food groups with regard to sex, age, lifestyle, health status including current diseases, immune functions such as natural killer cell activity and QOL. No significant difference was noted between the two groups in either study (data not shown).

\section{Occurrence of common colds and influenza}

A questionnaire was performed to examine the susceptibility of the subjects to infections in daily life. In the Funagata study, the common cold or influenza virus infections were observed in three subjects in the yoghurt group and eight subjects in the milk group. The risk of catching the common cold or influenza virus infection was about 3.4 times lower in the yoghurt group (OR $0 \cdot 29 ; P=0 \cdot 103$ ) than in the milk group.

In the Arita study, no influenza virus infection was noted in either group. The common cold was observed in seventeen subjects in the yoghurt group and twenty-five subjects in the milk group. The risk of catching the common cold was about 2.3 times lower in the yoghurt group (OR 0.44 ; $P=0 \cdot 084)$ than in the milk group.

We performed meta-analysis by integrating the results of these two studies. The results of meta-analysis showed that the risk of catching the common cold or influenza virus infection was about 2.6 times (significantly) lower in the
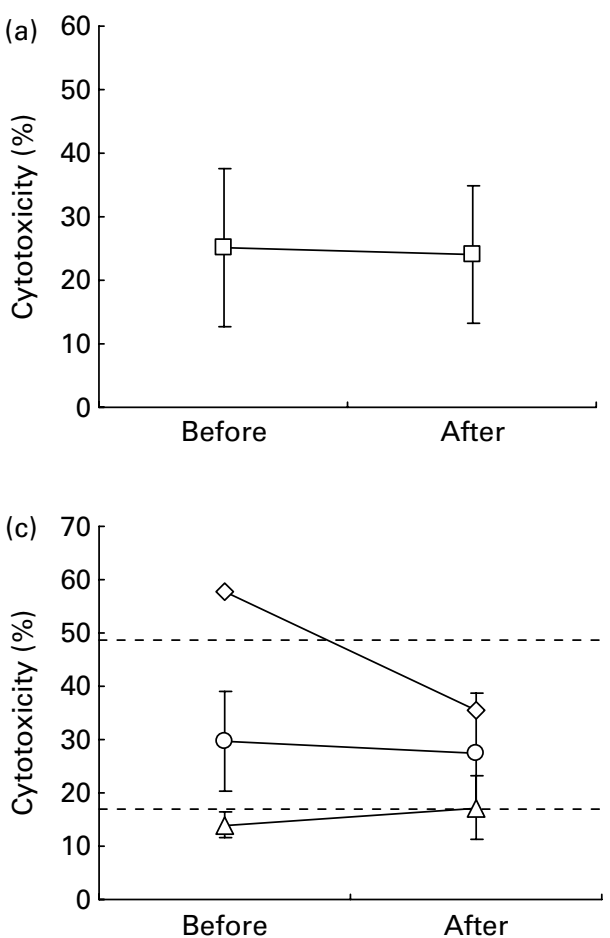

entire yoghurt group (OR 0.39; $P=0.019$ ) than in the milk group (Fig. 1).

\section{Effects on immune parameters}

In the Funagata study, the value of lymphocyte blastoid transformation induced by Con A increased significantly after intake in the yoghurt and milk groups, and this increase was significantly greater in the yoghurt group than in the milk group (Fig. 2). Natural killer cell activity also increased in the yoghurt group, but these increases were not significant (Fig. 3(b)). So, we analysed natural killer cell activity by classifying the subjects into normal-, low- and high-activity subject groups according to their natural killer cell activity at the beginning of intake because low natural killer cell activity has been shown to be associated with the development of infections in healthy elderly subjects ${ }^{(15)}$ and it has been reported that natural killer cell activity in subjects who have relatively low natural killer activity is enhanced by the intake of a probiotic strain $^{(7)}$. As a result, in the yoghurt group, the natural killer cell activity in the low-activity subject group increased significantly after intake until it was within the normal range (Fig. 3(d)). On the other hand, the natural killer cell activity in the normal-activity subject group was not affected as much and remained within the normal range after intake (Fig. 3(d)). The natural killer cell activity of the subjects in the high-activity group returned to within the normal range after intake (Fig. 3(d)). In the milk group, the natural killer activity showed similar changes to those in
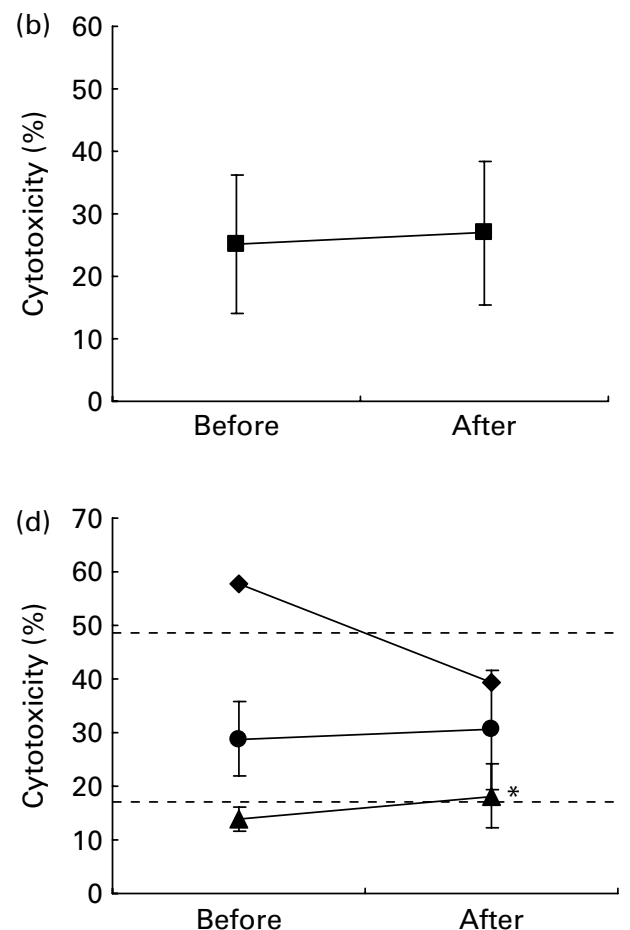

Fig. 3. Natural killer cell activity in the milk ( $n 28)(a, c)$ and yoghurt (fermented with Lactobacillus delbrueckii ssp. bulgaricus OLL1073R-1) ( $n$ 29) (b, d) groups in the Funagata study. The subjects were categorised into low-activity (milk group, $\Delta, n 10$; yoghurt group, $\mathbf{\Delta}, n 9$ ), normal-activity (milk group, $\bigcirc, n 17$; yoghurt group, $\bullet$, $n$ 19) and high-activity (milk group, $\diamond, n 1$; yoghurt group, $\diamond, n 1$ ) groups according to their natural killer cell activity before intake (c, d). Dashed lines represent the range of normal activity that has been defined by Mitsubishi Chemical Corp. as the range covering $95 \%$ of the natural killer cell activity of healthy individuals. Values are means, with standard deviations represented by vertical bars. ${ }^{*}$ Mean value was significantly different from that before the intervention $(P<0.05)$. 

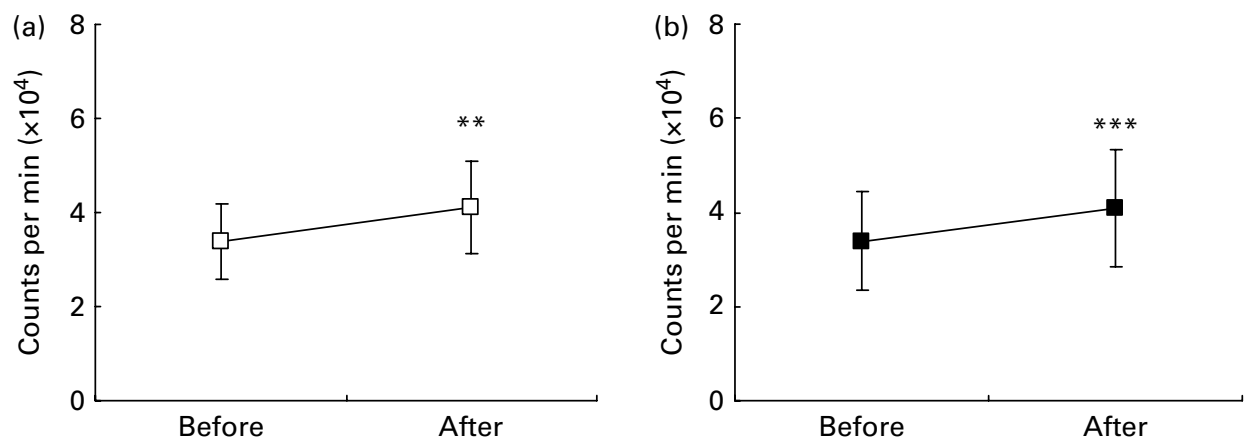

Fig. 4. Lymphocyte blastoid transformation in the milk ( $n$ 42) (a) and yoghurt (fermented with Lactobacillus delbrueckii ssp. bulgaricus OLL1073R-1) ( $n$ 43) (b) groups in the Arita study. Values are means, with standard deviations represented by vertical bars. Mean value was significantly different from that before the intervention: ${ }^{* *} P<0.01,{ }^{\star * \star} P<0.001$.

the yoghurt group, but no significant increase was detected after intake in any subject group (Fig. 3(c)).

In the Arita study, lymphocyte blastoid transformation by Con A (Fig. 4) and natural killer cell activity (Fig. 5(a) and (b)) significantly increased after intake in both groups, but these increases were not significantly different between the groups. The natural killer cell activity in the low-activity subject groups increased after intake, and the value was within the normal range in both groups as in the Funagata study (Fig. 5(c) and (d)). The increase in the yoghurt group was significant, but in the milk group there were only two subjects in the low-activity subject group. In the normal-activity subjects, it also increased significantly in both groups but stayed within the normal range (Fig. 5(c) and (d)). On the other hand, in the high-activity subjects, no marked changes were observed in either group, and the values remained within the high range (Fig. 5(c) and (d)).

We performed a meta-analysis by integrating the results of these two studies. The results of the meta-analysis showed that the increase in natural killer cell activity was significantly higher in the yoghurt group compared with the milk group $(P=0 \cdot 028)$.

\section{Effects on quality of life in the Arita study}

After intake, when compared with the values before the intake, the total score of the forty-six items increased significantly in both groups, and the scores of ten items showed significant
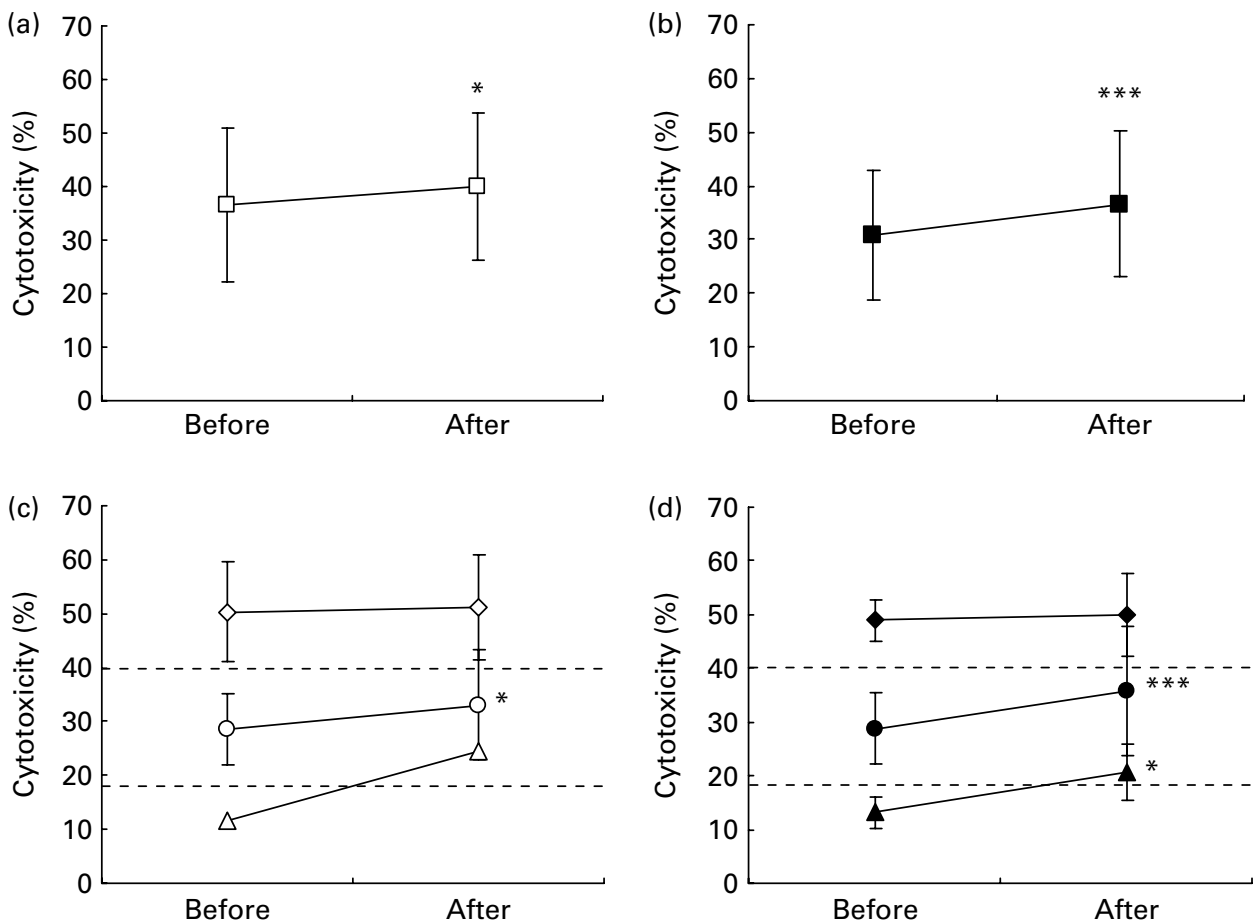

Fig. 5. Natural killer cell activity in the milk ( $n$ 42) (a, c) and yoghurt (fermented with Lactobacillus delbrueckii ssp. bulgaricus OLL1073R-1) ( $n$ 43) (b, d) groups in the Arita study. The subjects were categorised into low-activity (milk group, $\Delta, n 2$; yoghurt group, $\boldsymbol{\Lambda}, n 6$ ), normal-activity (milk group, $\bigcirc, n 23$; yoghurt group, $\bullet$, $n$ 28) and high-activity (milk group, $\diamond, n 17$; yoghurt group, $\diamond, n 9$ ) groups according to their natural killer cell activity before intake (c, d). Dashed lines represent the range of normal activity that has been defined by SRL Inc. as the range covering $95 \%$ of the natural killer cell activity of healthy individuals. Values are means, with standard deviations represented by vertical bars. Mean value was significantly different from that before the intervention: ${ }^{\star} P<0.05$, ${ }^{\star \star \star} P<0.001$. 
Table 2. Quality of life (QOL) scores before the beginning and after the end of milk or yoghurt (fermented with Lactobacillus delbrueckii ssp. bulgaricus OLL1073R-1) intake in the Arita study*

(Mean values and standard deviations)

\begin{tabular}{|c|c|c|c|c|c|c|c|c|c|c|}
\hline \multirow[b]{3}{*}{ Items } & \multicolumn{5}{|c|}{ Milk group ( $n$ 42) } & \multicolumn{5}{|c|}{ 1073R-1 yoghurt group $(n 43)$} \\
\hline & \multicolumn{2}{|c|}{ Before } & \multicolumn{2}{|c|}{ After } & \multirow[b]{2}{*}{$P \dagger$} & \multicolumn{2}{|c|}{ Before } & \multicolumn{2}{|c|}{ After } & \multirow[b]{2}{*}{$P \dagger$} \\
\hline & Mean & SD & Mean & SD & & Mean & SD & Mean & SD & \\
\hline Lacks general motivation & 3.7 & 0.6 & 3.7 & 0.7 & 0.745 & 3.4 & 0.9 & 3.8 & 0.6 & 0.006 \\
\hline Irritation & 3.5 & 0.7 & 3.8 & 0.5 & 0.013 & 3.2 & 0.8 & 3.6 & 0.8 & 0.007 \\
\hline Stress & 3.4 & 0.8 & 3.5 & 0.8 & 0.672 & 3.2 & 0.9 & 3.6 & 0.8 & 0.038 \\
\hline Waking at night & $2 \cdot 8$ & 1.1 & 3.0 & 1.1 & 0.257 & $2 \cdot 8$ & 0.9 & $3 \cdot 2$ & 1.1 & 0.034 \\
\hline Waking early in morning & $3 \cdot 1$ & $1 \cdot 0$ & 3.5 & 0.8 & 0.022 & $3 \cdot 3$ & 0.9 & 3.5 & 0.9 & 0.139 \\
\hline Failure of memory & $2 \cdot 8$ & 0.9 & 3.5 & 0.7 & 0.001 & $3 \cdot 2$ & 0.9 & 3.5 & 0.8 & 0.007 \\
\hline Sluggish feeling & 3.5 & 0.7 & 3.8 & 0.6 & 0.049 & 3.6 & 0.7 & 3.7 & 0.6 & 0.123 \\
\hline Easily fatigued & $3 \cdot 1$ & $1 \cdot 0$ & 3.6 & 0.7 & 0.002 & $3 \cdot 3$ & 0.9 & 3.7 & 0.6 & 0.005 \\
\hline Leg swelling & 3.6 & 0.8 & 3.8 & 0.6 & 0.132 & 3.6 & 0.9 & 3.7 & 0.6 & 0.033 \\
\hline Urination at night & $3 \cdot 1$ & $1 \cdot 2$ & 3.5 & $1 \cdot 0$ & 0.009 & 2.9 & $1 \cdot 2$ & $3 \cdot 2$ & $1 \cdot 2$ & 0.079 \\
\hline Total score & 159.9 & $12 \cdot 7$ & 164.7 & $11 \cdot 6$ & 0.002 & $160 \cdot 7$ & $15 \cdot 8$ & $166 \cdot 6$ & $12 \cdot 6$ & 0.002 \\
\hline
\end{tabular}

* The four choices concerning each item were scored 4, 3, 2 and 1 in decreasing value in relation to QOL.

† Statistical differences were evaluated using Wilcoxon's signed-rank test.

increases in the yoghurt or milk groups (Table 2). In the yoghurt group, significant improvements were detected after intake in the scores for 'lacks general motivation', 'irritation', 'stress', 'waking at night', 'failure of memory', 'easily fatigued' and 'leg swelling'. The scores for 'irritation', 'failure of memory' and 'easily fatigued' also increased significantly in the milk group. In addition, in the milk group only, the scores for 'waking early in morning', 'sluggish feeling' and 'urination at night' increased significantly.

According to the topics of the questions, the forty-six items were grouped into organ categories and others, i.e. respiration, skin, mental condition, eye/nose/throat, kidney, digestive system, musculoskeletal system, and others (Table 1). In both groups, the 'mental condition' and 'kidney' organ category scores increased significantly after intake. Concerning the 'skin' organ category scores, a significant increase was detected in the milk group only (Table 3 ).

Moreover, the score for 'eye/nose/throat' after intake was significantly higher in the yoghurt group than in the milk group $(P=0.030)$ (Table 3$)$. No significant difference was observed in the other categories.

\section{Correlation analysis}

We analysed the correlations between the immune function parameters and QOL scores. As a result, the promotion of natural killer cell activity was found to be correlated with the total score for the forty-six items ( $r$ 0.203; $P=0.066)$. Moreover, a significant positive correlation was noted between the promotion of natural killer cell activity and the total score for 'eye/nose/throat' $(r 0 \cdot 255 ; P=0 \cdot 018)$.

\section{Safety}

In these studies, no adverse event that related to the intake of the test or reference food was noted.

\section{Discussion}

In the present study, the intake of yoghurt fermented with L. bulgaricus OLL1073R-1 (1073R-1 yoghurt) was found to significantly reduce the risk of catching the common cold in the elderly compared with reducing the risk with the intake

Table 3. Organ category scores before the beginning and after the end of milk or yoghurt (fermented with Lactobacillus delbrueckii ssp. bulgaricus OLL1073R-1) intake in the Arita study*

(Mean values and standard deviations)

\begin{tabular}{|c|c|c|c|c|c|c|c|c|c|c|c|}
\hline \multirow[b]{3}{*}{ Organ categories } & \multicolumn{5}{|c|}{ Milk group ( $n$ 42) } & \multicolumn{5}{|c|}{ 1073R-1 yoghurt group ( $n$ 43) } & \multirow[b]{3}{*}{$P \ddagger$} \\
\hline & \multicolumn{2}{|c|}{ Before } & \multicolumn{2}{|c|}{ After } & \multirow[b]{2}{*}{$P \dagger$} & \multicolumn{2}{|c|}{ Before } & \multicolumn{2}{|c|}{ After } & \multirow[b]{2}{*}{$P \dagger$} & \\
\hline & Mean & SD & Mean & SD & & Mean & SD & Mean & SD & & \\
\hline Respiration & $7 \cdot 3$ & 0.9 & 7.5 & 0.8 & 0.316 & $7 \cdot 3$ & $1 \cdot 2$ & $7 \cdot 5$ & 0.9 & 0.206 & 0.553 \\
\hline Skin & $10 \cdot 3$ & 1.8 & $10 \cdot 9$ & 1.7 & 0.021 & $10 \cdot 9$ & 1.4 & $11 \cdot 1$ & 1.5 & 0.405 & 0.465 \\
\hline Mental condition & 33.0 & 4.0 & $35 \cdot 1$ & 3.7 & 0.001 & $32 \cdot 8$ & $5 \cdot 0$ & $35 \cdot 6$ & $4 \cdot 1$ & $<0.001$ & 0.340 \\
\hline Eye/nose/throat & 23.6 & 3.5 & $23 \cdot 8$ & 3.0 & 0.671 & 24.9 & $2 \cdot 4$ & $25 \cdot 2$ & $2 \cdot 6$ & 0.438 & 0.030 \\
\hline Kidney & $17 \cdot 1$ & $2 \cdot 4$ & $18 \cdot 4$ & $2 \cdot 2$ & $<0.001$ & $16 \cdot 9$ & $2 \cdot 8$ & $18 \cdot 1$ & $2 \cdot 1$ & 0.002 & 0.438 \\
\hline Digestive system & $22 \cdot 3$ & 1.9 & $22 \cdot 4$ & 1.9 & 0.913 & $22 \cdot 6$ & $1 \cdot 8$ & $22 \cdot 9$ & 1.5 & $0 \cdot 141$ & $0 \cdot 210$ \\
\hline Musculoskeletal system & $13 \cdot 0$ & $2 \cdot 4$ & 13.5 & $2 \cdot 1$ & 0.082 & $12 \cdot 7$ & $3 \cdot 1$ & $13 \cdot 3$ & $2 \cdot 4$ & 0.369 & 0.781 \\
\hline
\end{tabular}

* The four choices concerning each item were scored 4, 3, 2 and 1 in decreasing value in relation to quality of life.

† Statistical differences were evaluated using Wilcoxon's signed-rank test.

$\ddagger$ Scores after intake were compared between the groups. Statistical differences were evaluated using the Mann-Whitney $U$ test. 
of milk. It is generally accepted that yoghurt and milk are beneficial foods for maintaining our health and some studies have demonstrated that the consumption of yoghurt may enhance the immune response, particularly in immunocompromised populations, such as the elderly ${ }^{(16)}$. Recently, immunostimulatory effects of probiotics were also evaluated eagerly and some of the probiotic strains were shown to be effective in infections in randomised double-blind controlled trials $^{(17-19)}$. In the elderly, L. johnsonii and L. casei were shown to reduce the duration of infections including of the airway and gastrointestinal tract ${ }^{(17,18)}$. The intake of a tablet containing L. gasseri, Bifidobacterium longum and B. bifidum was reported to shorten common cold episodes and reduce the severity of symptoms ${ }^{(19)}$. However, these studies concluded that the probiotics could reduce the duration of the infections but not the occurrence. Concerning yoghurt, Van de Water et al. demonstrated the role of yoghurt in the modulation of the immune system in a randomised controlled trial. Of their subjects, those who consumed $200 \mathrm{~g}$ yoghurt once per $\mathrm{d}$ for a year, as compared with either the same product heat-treated after fermentation or the exclusion of yoghurt products from the diet during the length of the study, showed a significant decrease in allergic symptoms but there were a large number of respiratory infections in all groups during the severe respiratory season ${ }^{(20)}$. Therefore, this is the first report that proves that the intake of yoghurt can reduce the risk of respiratory infections.

We previously showed that 1073R-1 yoghurt and its polysaccharides increased natural killer cell activity in experiments using mice ${ }^{(11)}$. Natural killer cells are believed to provide a substantial defence against viral infection ${ }^{(21,22)}$, and low natural killer cell activity was shown to be associated with the development of infections, for example, the common cold, acute bronchitis, pneumonia, and death due to infection in healthy elderly subjects ${ }^{(15)}$. Therefore, we believe that the effect of 1073R-1 yoghurt is mainly dependent on the immunostimulatory polysaccharides produced from L. bulgaricus OLL1073R-1. However, the cell body of L. bulgaricus OLL1073R-1 may also contribute to the effect of this yoghurt because the cell body has been reported to exert host-mediated anti-tumour activity in mice ${ }^{(8)}$ and some probiotics have been shown to enhance natural killer cell activity in elderly individuals $^{(5,23,24)}$.

With regard to natural killer cell activity, in the present study, we found a significant positive correlation between the promotion of natural killer cell activity and the total score for the 'eye/nose/throat' system, and these two parameters after intake were significantly higher in the 1073R-1 yoghurt group than in the milk group. As the higher scores for QOL in the present study indicate a much better than average QOL condition, 1073R-1 yoghurt was suggested to improve the QOL of the elderly by augmenting natural killer cell activity. However, the symptoms included in the QOL items are supposed to be affected by various factors other than immune functions. Further investigations will be needed to show the relationship between the promotion of natural killer cell activity and the improvement of the QOL.

In the milk group, $\mathrm{T}$ lymphocyte proliferation and natural killer cell activity also increased after the intake period. These changes were not considered to be basal changes caused by seasonal alterations because the two independent studies were conducted during different seasons (Funagata study, 13 March 2005-7 May 2005; Arita study, 14 November 2006-5 February 2007). Therefore, we believe that milk also exerts some immunostimulatory effects by supplying important nutrients. It is generally accepted that nutrition is an important determinant of immune function ${ }^{(25)}$. Cows' milk contains proteins, $\mathrm{Ca}$ and an abundance of vitamin $B_{12}$. In particular, vitamin $B_{12}$ has been reported to augment the natural killer cell activity of patients with vitamin $\mathrm{B}_{12}$-deficiency anaemia and to enhance the $\mathrm{T}$ cell proliferative response to Con $\mathrm{A}^{(26,27)}$. In addition, recently, a relationship between vitamin $B_{12}$ status and the risk of cognitive impairment and dementia has been noted ${ }^{(28-30)}$. It is very interesting that the QOL score for 'failure of memory' increased significantly after the intake in the both of 1073R-1 yoghurt and milk in the present study. Furthermore, tryptophan contained in milk proteins may also have contributed to increasing the immune system parameters in the elderly. Tryptophan is the precursor of melatonin which has been demonstrated to enhance immune functions in many animal species including human subjects ${ }^{(31,32)}$. In addition, the melatonin concentration in the blood exhibits a clear circadian rhythm, and its level falls gradually with age. In many individuals beyond 65 years of age, a day-night rhythm is almost absent ${ }^{(33)}$ and chronic sleep disturbances caused by these changes may be associated with mental health problems including $\mathrm{QOL}^{(34)}$. Therefore, the improvement in the 'mental condition'-associated scores in both the 1073R-1 yoghurt and milk groups may be dependent on the tryptophan supplementation from milk proteins.

In the 21 st century, we will face a rapidly ageing society, and, as seen from the calls for improved QOL rather than simple longevity, there is now a strong desire to achieve longevity with both health and true wellbeing. In addition, agerelated immune changes put older adults at much greater risk of impairment and death from infection, such as from influenza viruses or pneumonia ${ }^{(35,36)}$. In recent years, numerous studies have been published on the health-promoting effects of yoghurt and the bacterial cultures used in the production of yoghurt. Some studies using yoghurt, individual lactic acid bacteria species, or both showed promising health benefits for certain gastrointestinal conditions, including lactose intolerance, constipation, diarrhoeal diseases, colon cancer, inflammatory bowel disease, Helicobacter pylori infection and allergies ${ }^{(37)}$. In the present study, we have shown that the intake of the yoghurt fermented with L. bulgaricus OLL1073R-1 augmented natural killer cell activity and reduce the risk of respiratory infections. We believe that yoghurt fermented with L. bulgaricus OLL1073R-1 may be a new beneficial food for the elderly.

\section{Acknowledgements}

We thank the staff of the Health and Welfare divisions of Funagata town and Arita town for recruiting and managing the human subjects and the sample collection. We especially thank Hubit Genomix Inc. for their help with designing the studies and data analysis.

The authors' contributions were as follows: S. I., A. K., H. S. and N. O. designed the research; H. H. made the yoghurts and supplied the yoghurts and milks to the subjects; 
S. I. and A. K. conducted the research and analysed the data; S. M. wrote the paper. S. M. and S. I. had primary responsibility for the final content. All authors read and approved the final manuscript.

The present study received no specific grant from any funding agency in the public or non-for-profit sectors.

There is no conflict of interest associated with the present study.

\section{References}

1. Gavazzi G \& Krause KH (2002) Aging and infection. Lancet Infect Disease 2, 659-665.

2. Ben-Yasuda A \& Weksler ME (1992) Immune senescence: mechanisms and clinical implications. Cancer Invest $\mathbf{1 0}$, $525-531$.

3. Makinodan TS, James J, Inamizu T, et al. (1984) Immunologic basis for susceptibility to infection in aged. Gerontology $\mathbf{3 0}$, 279-289.

4. Goodwin JS (1995) Decreased immunity and increased morbidity in the elderly. Nutr Rev 53, S41-S46.

5. Gill HS, Rutherfurd KJ, Cross ML, et al. (2001) Enhancement of immunity in the elderly by dietary supplementation with the probiotics Bifidobacterium lactis HN019. Am J Clin Nutr 74, 833-839.

6. Sheih YH, Chang BL, Wang LH, et al. (2001) Systemic immunity-enhancing effects in healthy subjects following dietary consumption of the lactic acid bacterium Lactobacillus rhamnosus HN001. J Am Coll Nutr 20, 149-156.

7. Nagao F, Nakayama M, Muto T, et al. (2000) Effects of a fermented milk drink containing Lactobacillus casei strain Shirota on the immune system in healthy human subjects. Biosci Biotechnol Biochem 64, 2706-2708.

8. Ebina T, Ogama N \& Murata K (1995) Antitumor effects of Lactobacillus bulgaricus 878R. Biotherapy 9, 65-70.

9. Kitazawa H, Harata T, Uemura J, et al. (1998) Phosphate group requirement for mitogenic activation of lymphocytes by an extracellular phosphopolysaccharide from Lactobacillus delbrueckii ssp. bulgaricus. Int J Food Microbiol 40, 169-175.

10. Nishimura-Uemura J, Kitazawa H, Kawai Y, et al. (2003) Functional alternation of murine macrophage stimulated with extracellular polysaccharides from Lactobacillus delbrueckii ssp. bulgaricus OLL1073R-1. Food Microbiol 20, 267-273.

11. Makino S, Ikegami S, Kano H, et al. (2006) Immunomodulatory effects of polysaccharides produced by Lactobacillus delbrueckii ssp. bulgaricus OLL1073R-1. J Dairy Sci 89, 2873-2881.

12. Dubois M, Gilles KA, Hamilton JK, et al. (1956) Colorimetric method for determination of sugars and related substances. Anal Chem 28, 350-356.

13. Petitti DB (2000) Meta-analysis, Decision Analysis, and Cost-Effectiveness Analysis: Methods for Quantitative Synthesis in Medicine, 2nd ed. New York: Oxford University Press.

14. Cooper H and Hedges LV (editors) (1994) The Handbook of Research Synthesis. New York: Russell Sage Foundation.

15. Ogata K, An E, Shioi Y, et al. (2001) Association between natural killer cell activity and infection in immunologically normal elderly people. Clin Exp Immunol 124, 392-397.

16. Meydani SN \& Ha WK (2000) Immunologic effects of yogurt. Am J Clin Nutr 71, 861-872.

17. Fukushima Y, Miyaguchi S, Yamano T, et al. (2007) Improvement of nutritional status and incidence of infection in hospitalised, enterally fed elderly by feeding of fermented milk containing probiotic Lactobacillus johnsonii La1 (NCC533). Br J Nutr 98, 969-977.

18. Guillemard E, Tondu F, Lacoin F, et al. (2010) Consumption of a fermented dairy product containing the probiotic Lactobacillus casei $\mathrm{DN}-114001$ reduces the duration of respiratory infections in the elderly in a randomized controlled trial. Br J Nutr 103, $58-68$.

19. de Vrese M, Winkler P, Rautenberg P, et al. (2005) Effect of Lactobacillus gasseri PA 16/8, Bifidobacterium longum SP 07/3, B. bifidum MF 20/5 on common cold episodes: a double blind, randomized, controlled trial. Clin Nutr 24, 481-491.

20. Van de Water J, Keen CL \& Gershwin ME (1999) The influence of chronic yogurt consumption on immunity. $J$ Nutr 129, 1492S-1495S

21. Guffee J, Fan W \& Stein-Streilein J (1989) The role of natural killer cells in early defense to influenza virus infection by the intranasal route. In Natural Killer Cells and Host Defense, p. 124 [EW Ades and C Lopez, editors]. Basel, Switzerland: S. Karger.

22. Welsh RM \& Vargas-Cortes M (1992) Natural killer cells in viral infection. In The Natural Immune System: The Natural Killer Cell, pp. 107-150 [CE Lewis and JO McGee, editors]. New York: Oxford University Press.

23. Gill HS, Rutherfurd KJ \& Cross ML (2001) Dietary probiotic supplementation enhances natural killer cell activity in the elderly: an investigation of age-related immunological changes. J Clin Immunol 21, 264-271.

24. Takeda K, Suzuki T, Shimada SI, et al. (2006) Interleukin-12 is involved in the enhancement of human natural killer cell activity by Lactobacillus casei Shirota. Clin Exp Immunol 146, 109-115

25. Chandra RK (1997) Nutrition and the immune system: an introduction. Am J Clin Nutr 66, 460S-463S.

26. Tamura J, Kubota K, Murakami H, et al. (1999) Immunomodulation by vitamin $\mathrm{B}_{12}$, augmentation of $\mathrm{CD}^{+} \mathrm{T}$ lymphocytes and natural killer $(\mathrm{NK})$ cell activity in vitamin $\mathrm{B}_{12}$-deficient patients by methyl-B $\mathrm{B}_{12}$ treatment. Clin Exp Immunol 116, $28-32$.

27. Sakane T, Takeda S, Kotani H, et al. (1982) Effects of methyl- $\mathrm{B}_{12}$ on the in vitro immune function of human T lymphocytes. J Clin Immunol 2, 101-109.

28. Tucker KL, Qiao N, Scott T, et al. (2005) High homocysteine and low $\mathrm{B}$ vitamins predict cognitive decline in aging men: the Veterans Affairs Normative Aging Study. Am J Clin Nutr 82, 627-635.

29. Clarke R (2008) B-vitamins and prevention of dementia. Proc Nutr Soc 67, 75-81.

30. Vogiatzoglou A, Refsum H, Johnston C, et al. (2008) Vitamin $B_{12}$ status and rate of brain volume loss in dwelling elderly. Neurology 71, 826-832.

31. Nelson RJ (2004) Seasonal immune function and sickness responses. Trends Immunol 25, 187-192.

32. Garcia-Maurino S, Gonzalez-Haba MG, Calvo JR, et al. (1997) Melatonin enhances IL-2, IL- 6 , and IFN- $\gamma$ production by human circulating $\mathrm{CD}^{+}$cells. J Immunol 159, 574-581.

33. Karasek M \& Reiter RJ (2002) Melatonin and aging. Neuroendocrinol Lett 23, S14-S16.

34. Karasek M (2004) Melatonin, human aging, and age-related disease. Exp Gerontol 39, 1723-1729.

35. Castle SC (2000) Clinical relevance of age-related immune dysfunction. Clin Infect Dis 31, 578-585.

36. Yoshikawa TT (1983) Geriatric infectious diseases: an emerging problem. J Am Geriatr Soc 31, 34-39.

37. Adolfsson O, Meydani SN \& Russell RM (2004) Yogurt and gut function. Am J Clin Nutr 80, 245-256. 